\title{
BMJ Open Identification of the optimal treatment strategy for complex appendicitis in the paediatric population: a protocol for a multicentre prospective cohort study (CAPP study)
}

\author{
Paul van Amstel (D) , ${ }^{1}$ Roel Bakx, ${ }^{1}$ Johanna $\mathrm{H}$ van der Lee, ${ }^{2,3}$ \\ Marijke C van der Weide, ${ }^{4}$ Rik van Eekelen, ${ }^{5}$ Joep P M Derikx, ${ }^{1}$ \\ Ernest L W van Heurn, ${ }^{1}$ Ramon R Gorter, ${ }^{1}$ CAPP collaborative study group
}

To cite: van Amstel $P$, Bakx R, van der Lee JH, et al. Identification of the optimal treatment strategy for complex appendicitis in the paediatric population: a protocol for a multicentre prospective cohort study (CAPP study). BMJ Open 2022;12:e054826. doi:10.1136/ bmjopen-2021-054826

- Prepublication history and additional supplemental material for this paper are available online. To view these files, please visit the journal online (http://dx.doi.org/10.1136/ bmjopen-2021-054826).

Received 24 June 2021 Accepted 07 January 2022

Check for updates

(c) Author(s) (or their employer(s)) 2022. Re-use permitted under CC BY-NC. No commercial re-use. See rights and permissions. Published by BMJ.

For numbered affiliations see end of article.

Correspondence to

Paul van Amstel;

p.vanamstel@amsterdamumc.nl

\section{ABSTRACT}

Introduction In daily practice large heterogeneity in the treatment of children with complex appendicitis exists. Complex appendicitis can be divided into two subtypes; complex appendicitis with and without appendiceal mass and/or abscess. As complex appendicitis is associated with high morbidity and costs, identification of the optimal treatment strategy is essential. In this article, we present the study protocol for the CAPP (Complex Appendicitis in the Pediatric Population) study.

Methods and analysis This nation-wide, multi-centre, comparative, non-randomised prospective cohort study includes all children $<18$ years old with a preoperative suspicion of complex appendicitis, which is based on imaging confirmed acute appendicitis and predefined criteria regarding the severity of appendicitis. Eligible patients are recruited in more than 30 hospitals. Open appendectomy will be compared with laparoscopic appendectomy for children without appendiceal mass and/or abscess and initial non-operative treatment (ie, intravenous antibiotics with or without percutaneous drainage) to direct appendectomy for children with appendiceal mass and/or abscess. Based on historical data supplied by the participating hospitals and an inclusion period of 2 years and 9 months, a sample size of 1308 patients is aimed. Primary outcome is the proportion of patients experiencing any complication at 3 months follow-up. Reported complications will be assessed by an independent adjudication committee. Secondary outcomes include, but are not limited to, quality of life, and (in)direct costs. To adjust for baseline differences and selection bias, outcomes will be compared after propensity score analysis (inverse probability weighting and stratification).

Ethics and dissemination The Medical Ethics Review Committee of the Amsterdam UMC, location AMC, declared that the Medical Research involving Human Subjects Act (WMO) did not apply to this study. Therefore, no official approval was required by national law. Study results will be presented in peer-reviewed scientific journals and at (inter)national conferences.

Trial registration numbers NCT04755179; NL9371.
Strengths and limitations of this study

- Generalisable data were gathered from a large cohort of children treated for acute complex appendicitis according to standardised treatment strategies in more than 30 academic and (large) teaching hospitals in the Netherlands.

- Study protocol designed by a multidisciplinary team consisting of epidemiologists, paediatricians, infectiologists, gastroenterologists, (interventional) radiologists, patient support groups and (paediatric) surgeons.

- Assessment of all complications and severity by an independent adjudication committee.

- Although identified confounders will be taken into account in a propensity score analysis, the nonrandomised study design potentially allows for confounding by indication.

\section{INTRODUCTION}

Acute appendicitis is one of the most common gastrointestinal disorders with a lifetime incidence of $7 \%-9 \% .^{12}$ It is frequently encountered in children, as in the Netherlands approximately one-third of all patients with acute appendicitis are under the age of 20 years. ${ }^{3}$ Insights in the pathogenesis of appendicitis have led to the recognition of two distinct types: simple (or uncomplicated) and complex (or complicated) appendicitis. ${ }^{4-6}$ Current research projects worldwide mainly focus on the treatment of simple appendicitis questioning the necessity of appendectomy. However, in daily clinical practice large heterogeneity exists in the treatment of complex appendicitis, a disease that is associated with morbidity in up to $30 \%$ of patients, prolonged hospital stay and high costs. ${ }^{3}$ Identification of the optimal treatment of complex appendicitis 
is therefore essential. Complex appendicitis can be divided into two subtypes: complex appendicitis without mass and/ or abscess formation and complex appendicitis with mass and/or abscess formation.

Although (inter)national guidelines agree that appendectomy is recommended for children presenting with complex appendicitis without appendiceal mass and/or abscess, the optimal surgical approach (laparotomy or laparoscopy) is unclear. ${ }^{78}$ In recent times laparoscopic appendectomy is increasingly applied in both adults $(80 \%)$ and children $(60 \%) .{ }^{3} 9$ Potential benefits reported for this approach (compared with open appendectomy) are, but not limited to, less superficial site infection, reduced length of hospital stay and less postoperative bowel obstruction. The presumed higher incidence of postoperative intra-abdominal abscess formation seems the reason that some surgeons are reluctant to use the laparoscopic approach. However, the level of evidence on this topic is low and inconsistency in results is found between studies. ${ }^{10}$

Evidence regarding the treatment of children presenting with complex appendicitis with mass and/or abscess formation is scarce as well. Some surgeons favour direct appendectomy, whereas others prefer an initial non-operative approach consisting of intravenous antibiotics with or without (percutaneous) abscess drainage. A Cochrane review only included two randomised controlled trials and stated that no firm conclusions could be drawn on the optimal treatment (direct appendectomy or initial non-operative treatment) of children with complex appendicitis with mass and/or abscess formation. ${ }^{11}$ Another systematic review, including seven historical cohort studies that reported on cohorts of children that were treated either non-operatively or by direct appendectomy, concluded that non-operative treatment led to fewer complications, specifically superficial site infection and postoperative intra-abdominal abscess formation, compared with direct appendectomy. ${ }^{12}$ Contrarily, the Dutch national guideline (2019) for the diagnosis and management of appendicitis recommends to perform direct appendectomy in children, which is purely based on expert opinion. $^{13}$

The lack of high-quality data regarding the management of complex appendicitis in the paediatric population emphasises the need for well-designed studies in order to identify the optimal treatment strategy for complex appendicitis in the paediatric population. The aim of this study is twofold; first, to evaluate the outcomes (in terms of complications, health-related quality of life (Hr-QoL) and costs) of open appendectomy compared with laparoscopic appendectomy for children with complex appendicitis without appendiceal mass and/or abscess. Second to compare the outcomes (in terms of complications, Hr-QoL and costs) of initial non-operative treatment (ie, intravenous antibiotics with or without percutaneous drainage) with direct appendectomy for children with complex appendicitis with appendiceal mass and/or abscess. Here, we present the protocol for this observational study, registered at Clinical-Trials.gov on 29 January 2021 and the Netherlands Trial Register on 4 April 2021.

\section{METHODS AND ANALYSIS}

\section{Study design and patient involvement}

'The identification of the optimal treatment strategy for Complex Appendicitis in the Pediatric Population' (CAPP) study is a nationwide, multi-centre, comparative, nonrandomised prospective cohort study with standardised treatment strategies. The choice of treatment is jointly decided by the physician and the patient/parents, and subsequently a standardised treatment strategy is followed. Data are collected during admission, at 1 and 3 months after inclusion.

Patients, parents and patient support groups were involved at several stages of the study design. The Dutch Foundation Child and Hospital advised on study design, supported protocol drafting and will be involved in dissemination of the main results of this study to participants and public. Outcome measures for this study were determined according to the core outcome set for clinical trials investigating any treatment of acute simple appendicitis. Patients and parents were involved in focus groups and consensus meetings in which the core outcome set was developed. ${ }^{14}$

\section{Patient selection}

Eligible for inclusion are all children $<18$ years old that need to undergo treatment for the suspicion of complex appendicitis. Preoperative suspicion of complex appendicitis is based on imaging confirmed acute appendicitis and the following predefined criteria (regarding the severity of appendicitis):

- Four points or more on the complex appendicitis prediction score. $^{15}$ OR

- High suspicion of complex appendicitis by the treating physician. In this case, the treating physician is requested to record (before treatment) the clinical, biochemical or radiological variable underlying the suspicion.

\section{Complex appendicitis prediction score}

The complex appendicitis prediction score is a paediatric scoring system that predicts the probability of complex appendicitis. ${ }^{15}$ This scoring system with a scale ranging from 0 to 10, consists of five preoperative variables (each awarded points): diffuse abdominal guarding (three points), C-reactive protein level $>38 \mathrm{mg} / \mathrm{L}$ (two points), signs of complex appendicitis on ultrasound (two points), temperature $>37.5^{\circ} \mathrm{C}$ (one point) and more than 1 day of abdominal pain (two points). In an independent validation in a paediatric cohort, this scoring system had a diagnostic accuracy of $91 \%$ (95\% CI $84 \%$ to $98 \%$ ), $90 \%$ (95\% CI $54 \%$ to $99 \%$ ) sensitivity, $91 \%$ (95\% CI $79 \%$ to $97 \%$ ) specificity, positive likelihood ratio of $10(95 \%$ CI 4.19 to 23.42) and negative likelihood ratio of 0.11 (95\% CI 0.02 to 0.71$).{ }^{15}$

\section{Subgroups of complex appendicitis}

Patients will be classified into the two subgroups of complex appendicitis based on clinical and radiological 


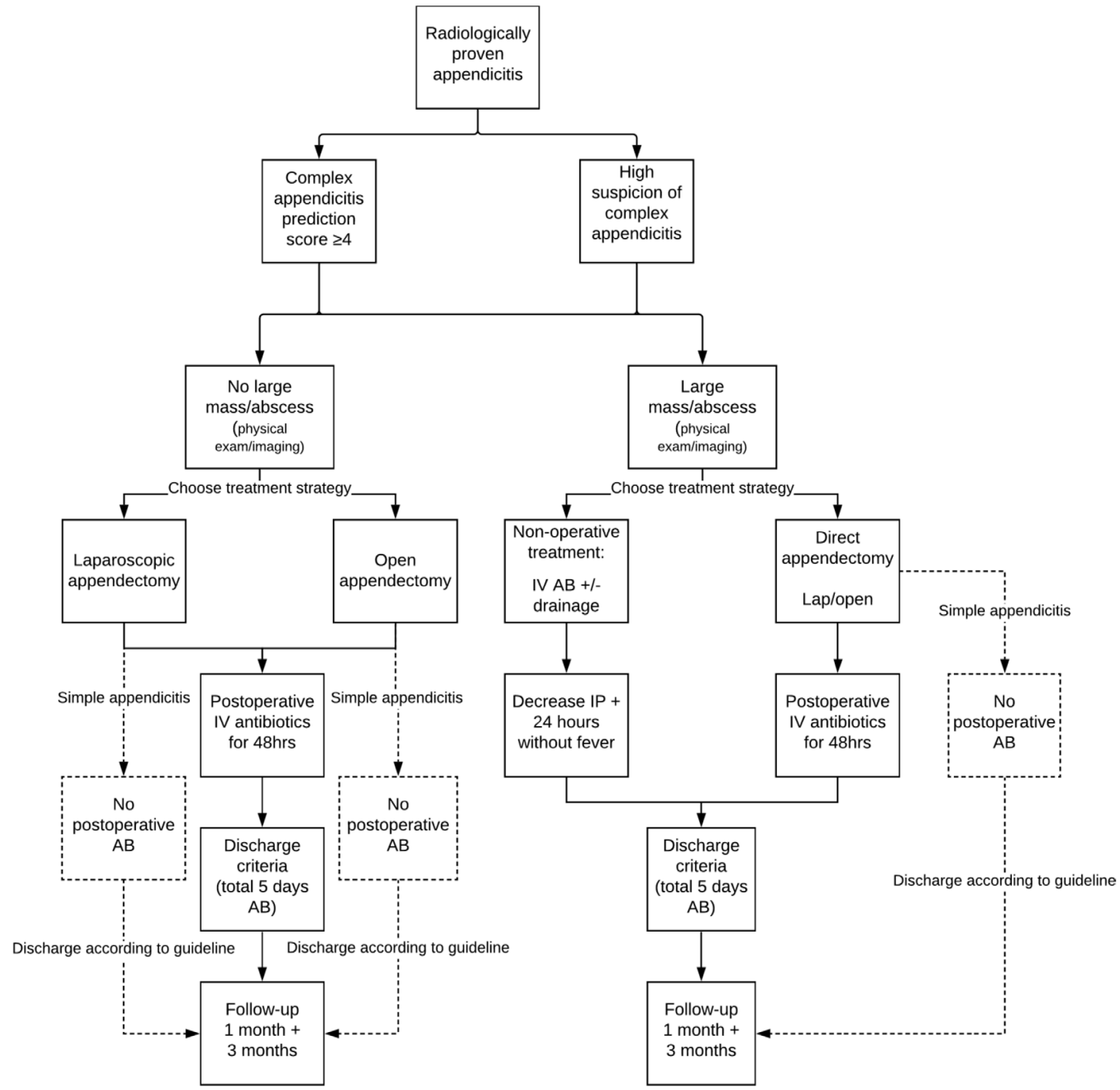

Figure 1 Flowchart of standardised treatment protocol.

features. If no enlarged mass is found during physical examination and no appendiceal abscess is present on additional imaging, patients will be categorised as subgroup 1 (complex appendicitis without abscess or mass). In this subgroup laparoscopic appendectomy will be compared with open appendectomy. If signs suggestive of intra-abdominal abscess and/or enlarged mass are present, patients will be categorised as subgroup 2 (complex appendicitis with abscess or mass). Initial non-operative treatment will be compared with direct appendectomy (laparoscopic or open) in this subgroup. See figure 1 for a flowchart displaying the management strategies.

\section{Study setting and feasibility}

Eligible patients are recruited in more than 30 hospitals, both academic and large peripheral teaching hospitals, across the Netherlands. Inclusion started on 12 August 2019.

Based on data supplied by the participating hospitals, approximately 634 children per year are expected to meet the inclusion criteria. As this is an observational study, we expect a participation rate of $75 \%$. Taking into account an inclusion period of 2 years and 9 months we expect 1308 children to participate in this study.

The expected distribution of patients with complex appendicitis without abscess/mass (subgroup 1) and patients with abscess/mass (subgroup 2) is $75 \%$ versus $25 \% .^{39}$ Thus it is expected that 981 children will be included in subgroup 1 and 327 in subgroup 2.

Diagnostic work-up and treatment of all children with complex appendicitis will be in line with the recommendations of the Dutch national guideline. ${ }^{13}$

\section{Sample size calculation}

Based on the expected inclusion of 981 children with complex appendicitis without abscess/mass and assuming a distribution of open versus laparoscopic surgery of $40 \%$ versus $60 \%$, an absolute difference in overall complications of $7.3 \%$ between the two treatment strategies can be detected with a power of $80 \%$ and a significance level of $5 \%$. This difference in overall complications would be clinically relevant, and if detected in this study, would 
Table 1 Key points standardised treatment strategies

\begin{tabular}{|c|c|c|}
\hline Laparoscopic appendectomy & Open appendectomy & Non-operative treatment \\
\hline $\begin{array}{l}\text { Conventional laparoscopy (three-trocar } \\
\text { technique) }\end{array}$ & Gridiron incision at McBurney & $\begin{array}{l}\text { At least } 48 \text { hours of intravenous } \\
\text { antibiotics (type of antibiotics according } \\
\text { to local protocol) }\end{array}$ \\
\hline $\begin{array}{l}\text { Only suction and no peritoneal lavage in } \\
\text { case of purulent fluid }\end{array}$ & $\begin{array}{l}\text { Abdominal wall protection after obtaining } \\
\text { access to the abdominal cavity }\end{array}$ & $\begin{array}{l}\text { Clinical evaluation of vital parameters } \\
\text { every } 8 \text { hours }\end{array}$ \\
\hline $\begin{array}{l}\text { Treatment of the mesoappendix with } \\
\text { coagulation or clips }\end{array}$ & Appendiceal stump closure by ligation & $\begin{array}{l}\text { The decision to perform percutaneous/ } \\
\text { surgical drainage of an appendiceal } \\
\text { abscess is made by the treating surgeon }\end{array}$ \\
\hline $\begin{array}{l}\text { Appendiceal stump closure: Two } \\
\text { endoloops. In case of involvement of the } \\
\text { appendiceal base, the use of endostapler } \\
\text { is recommended. }\end{array}$ & Closure of wounds as appropriate & $\begin{array}{l}\text { Prior to removal of the drainage tube, } \\
\text { imaging studies will be obtained to } \\
\text { confirm the resolution of the abscess }\end{array}$ \\
\hline \multicolumn{3}{|l|}{$\begin{array}{l}\text { Withdrawal of appendix through trocar or } \\
\text { with an endobag }\end{array}$} \\
\hline
\end{tabular}

lead to changes in surgical approach for children with complex appendicitis without mass and/or abscess.

As described, it is expected that 327 children with complex appendicitis with abscess/mass formation will be included in the CAPP study. With 327 included patients in subgroup 2 and assuming a distribution of non-operative treatment versus direct appendectomy of $20 \%$ versus $80 \%$, an absolute difference in overall complications of $16.4 \%$ between the treatment strategies can be detected with a power of $80 \%$ and a significance level of $5 \%$. If detected, this difference would be clinically relevant, leading to changes in the standard treatment strategy for children with appendiceal mass and/or abscess.

\section{Standardised treatment strategies}

Standardised treatment protocols were developed in order to reduce the heterogeneity in treatment between the participating hospitals. All participating sites agreed to conform to these standardised treatment protocols to the best of their ability. These standardised treatments are completely based on the recommendations given in the Dutch national guideline regarding the preoperative, perioperative and postoperative care. See table 1,Box 1 ,

\section{Box 1 Predefined discharge criteria}

Discharge criteria equal for all treatment strategies

- Body temperature $<38^{\circ} \mathrm{C}$.

- NRS $<4$.

- Adequate oral intake.

- Able to mobilise.

Additional discharge criteria for non-operative treatment strategy

- Decreased leucocytosis.

Decreased C-reactive protein.

NRS, Numeric Rating Scale. and online supplemental appendix 1 for a detailed description of the treatment strategies. All key points of the treatment strategies that are described in table 1 , Box 1, and online supplemental appendix 1 are recommendations of the Dutch national guideline.

\section{Study outcomes}

Primary outcome

The primary outcome is defined as the proportion of patients experiencing any complication within 3 months after inclusion. An independent adjudication committee will review all reported complications to determine whether or not they meet the definition of complications and to assess their relation to treatment. This committee will categorise all complications according to the ClavienDindo scale. $^{16}$

The following events will be considered as complications, but the list is not exhaustive:

- Superficial site infection: criteria according to the CDC guidelines. ${ }^{17}$

- Intra-abdominal abscess: radiologically confirmed fluid collection containing pus or infected material that is surrounded by inflamed tissue.

- Stump leakage: radiologically confirmed intraabdominal fluid collections after appendectomy.

- Stump appendicitis: radiologically confirmed recurrence of disease after appendectomy.

- Secondary/prolonged bowel obstruction (including paralytic ileus) confirmed by imaging or perioperative diagnosis with the need for treatment. For instance, a patient requiring gastrointestinal decompression with a nasogastric tube.

- Anaesthesia-related complications, such as pneumonia.

- Incisional hernia: any abdominal wall gap with or without a bulge in the area of a postoperative scar 
perceptible or palpable by clinical examination or imaging.

- Need for additional surgical or radiological interventions related to the primary disease (appendicitis).

- Readmission for an indication related to appendicitis. Such as readmissions for recurrent/residual appendicitis, and clinical observation of fever and abdominal pain.

\section{Secondary outcomes}

Follow-up will take place at 30 days and 3 months after inclusion to evaluate the secondary outcomes. The secondary outcomes of this study are listed below.

\section{Treatment-related endpoints}

- Proportion of patients experiencing any complication during admission.

- Proportion of patients experiencing any complication within 30 days after inclusion.

- Proportion of patients with a postoperative intraabdominal abscess within 3 months after inclusion.

- Proportion of patients with a superficial site infection within 3 months after inclusion.

- Proportion of patients with a secondary/prolonged bowel obstruction within 3 months after inclusion.

- Proportion of patients not having to undergo appendectomy within 3 months after inclusion.

- Proportion of patients experiencing recurrent appendicitis within 3 months after inclusion (histopathologically confirmed).

- Proportion of patients experiencing early failure of non-operative treatment, defined as those patients that undergo appendectomy during the antibiotic course (intravenous or oral) due to persistent complaints, clinical deterioration or faecolith.

- Proportion of patients that undergo interval appendectomy within 3 months after inclusion (histopathologically no sign of recurrent appendicitis).

\section{Patient-related endpoints}

- Level of pain: assessed by the Numeric Rating Scale and total use of pain medication during admission.

- Health-related Quality of Life (Hr-QoL) measured by the validated European Quality of Life-5 DimensionsYouth, European Quality of Life-5 Dimensions-Proxy questionnaires and Pediatric Quality of Life Inventory 4.0 at admission, 30 days and 3 months after inclusion. $^{18} 19$

- Patient satisfaction measured by the Net Promoter Score and the validated Patient Satisfaction Questionnaire (PSQ-18). ${ }^{20}$

- Number of days absent from school, social or sport events (patient level).

- Number of days absent from work (parent level).

- Total number of extra visits (not the already scheduled ones) to the outpatient clinic, general practitioner's office or emergency department for abdominal pain within 3 months after inclusion.
- Total length of hospital stay during follow-up period for strategy related treatment or complications.

\section{Cost-related endpoints}

- Non-medical and indirect costs until 3 months after inclusion measured by the Medical Consumption Questionnaire (iMCQ) and the Productivity Cost Questionnaire (iPCQ) adapted for use in children and parents. ${ }^{21} 22$

- Direct (actual) healthcare costs measured by variables such as number of outpatient visits, in-hospital generated costs, number of general practitioner visits, and number of emergency department visits.

\section{Statistical analysis plan}

General principles

Analysis of the primary and secondary outcomes will be performed after the final follow-up moment of the last patient, and after data cleaning for these outcomes has been completed. Recruitment of patients will be presented using a flow diagram as shown in figure 2. For the primary analysis all patients with a preoperative diagnosis of complex appendicitis will be included. Subsequently only patients with a perioperative and/ or histopathologically confirmed complex appendicitis as classified by the criteria proposed by Bhangu et $a l$, will be included in a secondary analysis. ${ }^{23}$ Furthermore, patients with complex appendicitis with mass and/or abscess (subgroup 2) that are treated by direct appendectomy will be divided by surgical approach (laparoscopic or open) in a secondary analysis in order to investigate the influence of surgical approach on primary and secondary outcomes in this subgroup.

To estimate the effect of treatments, adjusted for potential confounders, a propensity score method will be applied in both subgroups. ${ }^{24}$ Directed Acyclic Graphs (DAGs) were created to identify potential patient-related confounding variables (figures 3 and 4). Identified variables for subgroup 1 are age, body mass index (BMI), comorbidity, ASA classification, preoperative systemic inflammatory response syndrome, time of presentation (day/night and weekday/weekend), duration of abdominal pain, and the surgeon's preference for one of both treatment strategies. For subgroup 2 age, BMI, comorbidity, preoperative systemic inflammatory response syndrome, time of presentation (day/night and weekday/weekend), size of the abscess on imaging and the surgeon's preference for one of both treatment strategies were found to be the most important potential confounding variables. These variables will be collected preoperatively using standardised forms. Inverse probability of treatment weighting (IPTW) will be applied to estimate treatment effect adjusted for the identified covariates. Subsequently, sensitivity analysis will be performed by propensity score stratification, in which each patient will be classified into one of the five equally sized propensity score strata. The strata are formed by the quintiles of the observed propensity 


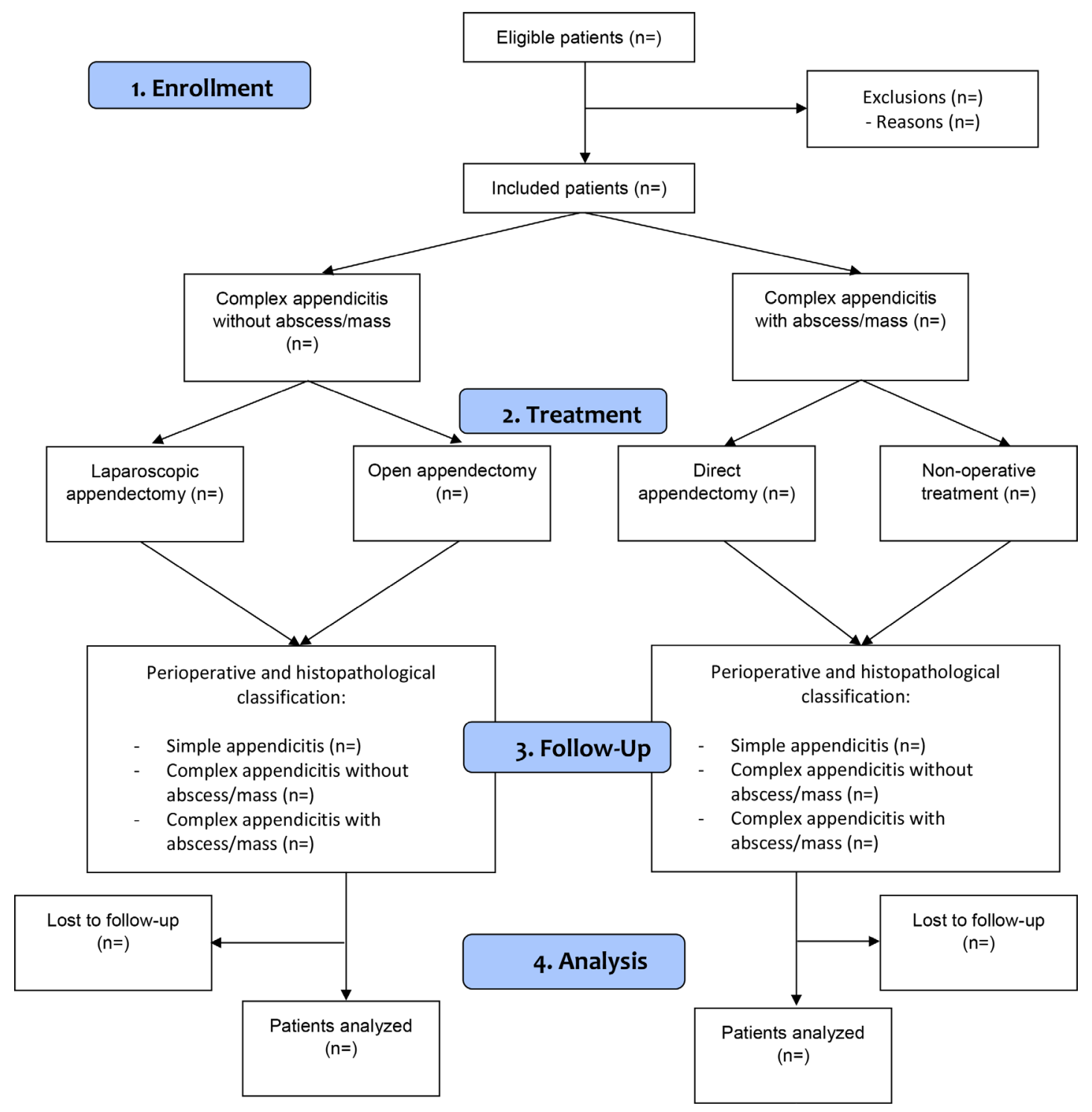

Figure 2 Patient flowchart.

score distribution. The treatment effect and its variance will be estimated in each stratum. Effects and variances will then be pooled by taking their average across strata.

We will examine the overlap of propensity scores in the treatment groups as well as the balancing property of propensity scores. To examine overlap, the empirical distributions of the linearised propensity score will be compared between treatment groups. Balancing will be assessed by comparing the standardised differences in covariates in means for continuous variables and in percentages for dichotomous variables within (a) the groups obtained after IPTW and (b) each propensity score stratum. Insignificant differences $(p<0.05)$ or low standardised mean differences $(<0.1)$ support the assumption of balance between the treatment groups. $^{25} 26$

\section{Baseline characteristics}

Baseline characteristics will be presented for the total population (patients with a preoperative suspicion of complex appendicitis) as treated, using the format as presented in tables 2 and 3. Data will be presented using absolute numbers and percentages for discrete outcomes. Continuous outcomes will be presented as means with SD or medians with IQRs, according to their distribution. Baseline characteristics will be compared between treatment groups and presented for both the prematching cohort and postmatching cohort. For each subgroup of complex appendicitis a baseline characteristics table will be created.

\section{Primary endpoint analysis}

Proportion of complications after 3 months will be compared for both subgroups of preoperatively suspected complex appendicitis (subgroup 1 and 2 as described). Data on the primary outcome will be presented as shown in tables 4 and 5 .

Unadjusted and propensity score adjusted differences in proportions and ORs will be presented with their $95 \%$ CIs. 


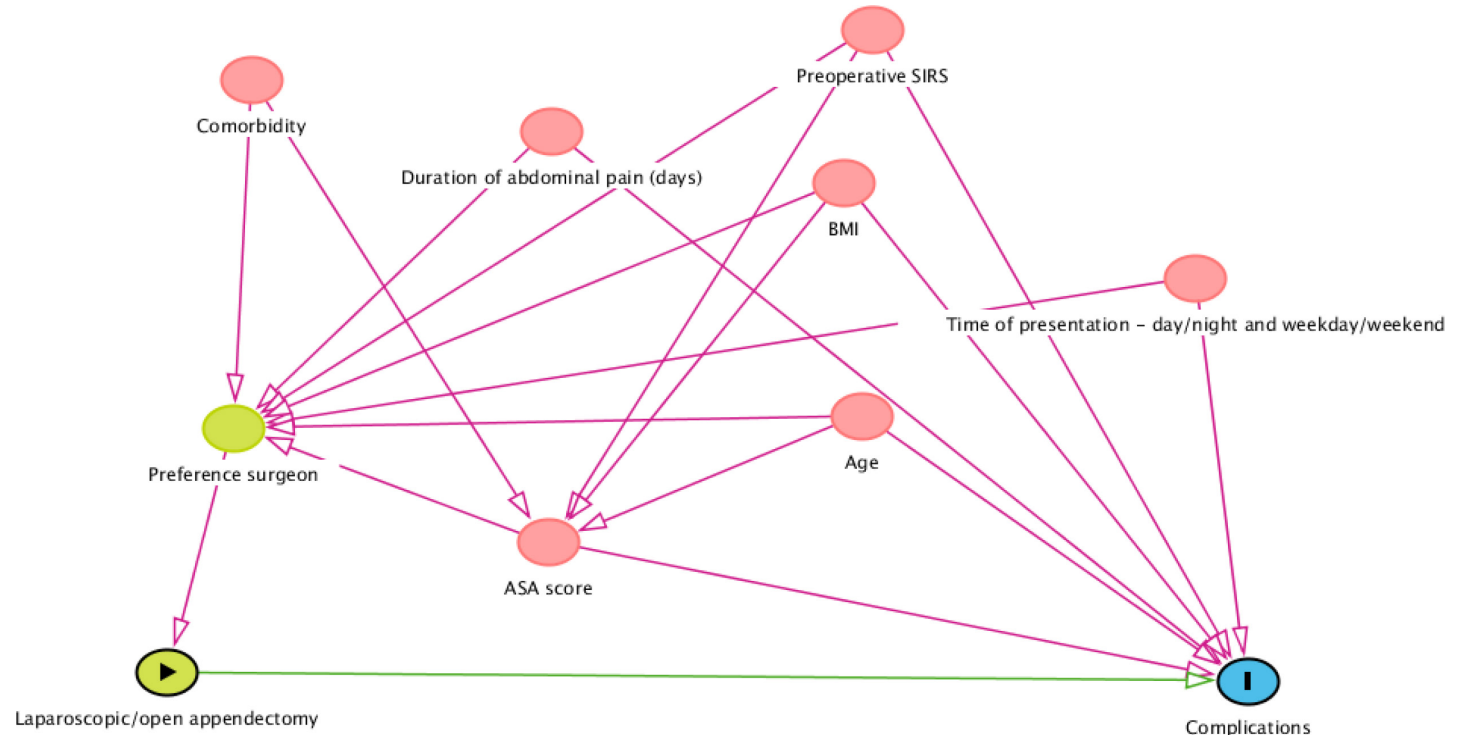

Figure 3 Direct Acyclic Graph subgroup 1. ASA, American Society of Anesthesiologists. BMI, Body Mass Index. SIRS, Systemic Inflammatory Response Syndrome.

\section{Secondary endpoints analysis}

Data on the secondary outcomes will be presented as displayed in tables 6 and 7. Unadjusted and propensity score adjusted ORs and mean differences for continuous outcomes will be presented with their $95 \%$ CI.

\section{Cost-effectiveness analysis}

In this study, cost-effectiveness and cost-utility will be assessed. Utility will be measured by the EQ-5D-Proxy, and EQ-5D-Y at admission, 1 month, and 3 months. In this way both the child's and parents' perspective will be assessed. No difference in effect is anticipated after 3 months, as acute appendicitis is an acute disease with a relatively short period of disutility.

Costs will be assessed from the societal perspective, integrating healthcare costs and societal costs (loss of productivity). Integrated costs, consisting of direct medical costs, indirect medical costs and indirect costs, will be evaluated for each treatment strategy. For this purpose, data will be gathered by iMCQ and iPCQ questionnaires at admission and 3 months. In addition, secondary data will be gathered from the patients' medical chart and financial information system from the participating hospitals. Adjustment for inflation will be made using the price-index-indices as provided by statline.cbs.nl.

\section{Outcome analysis}

In the cost-effectiveness analysis, the incremental costeffectiveness ratio (ICER) will be calculated representing the difference in costs between the two treatments relative to the difference in the proportion of patients with a complication. Next to the ICER, net monetary benefit will

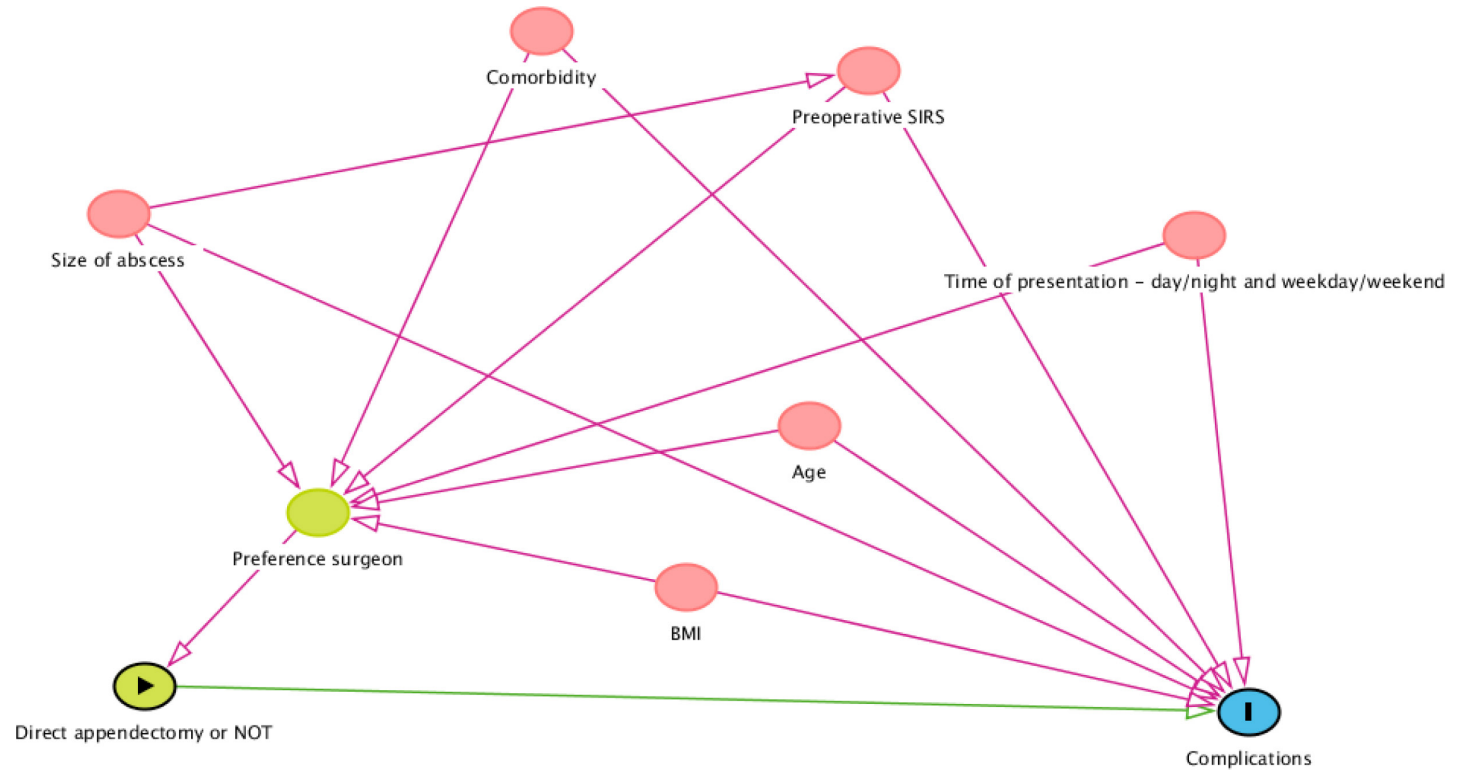

Figure 4 Direct Acyclic Graph subgroup 2. BMI, Body Mass Index. SIRS, Systemic Inflammatory Response Syndrome 
Table 2 Baseline characteristics subgroup 1

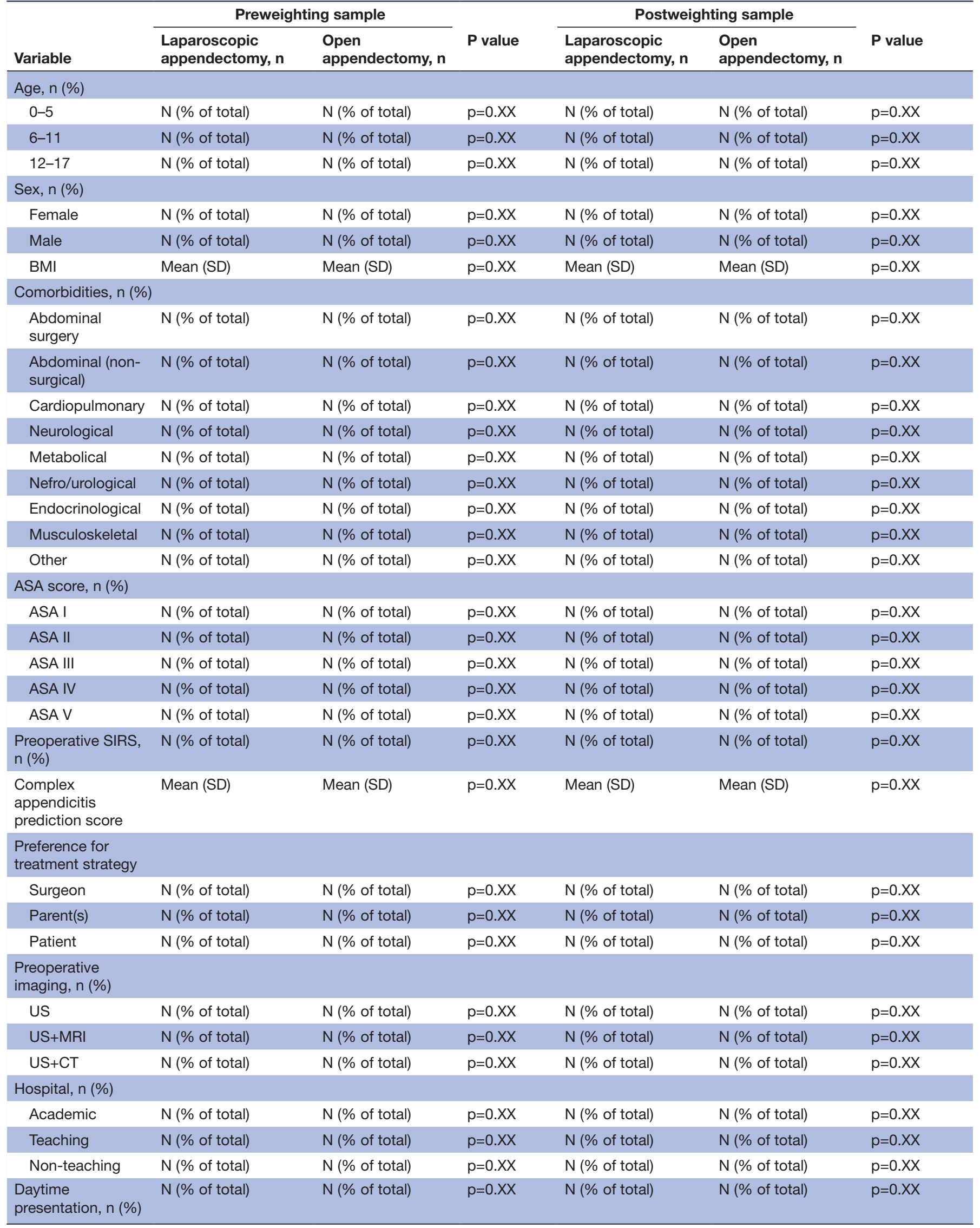


Table 2 Continued

\begin{tabular}{|c|c|c|c|c|c|c|}
\hline \multirow[b]{2}{*}{ Variable } & \multicolumn{2}{|c|}{ Preweighting sample } & \multirow[b]{2}{*}{$P$ value } & \multicolumn{2}{|c|}{ Postweighting sample } & \multirow[b]{2}{*}{$P$ value } \\
\hline & $\begin{array}{l}\text { Laparoscopic } \\
\text { appendectomy, } n\end{array}$ & $\begin{array}{l}\text { Open } \\
\text { appendectomy, } n\end{array}$ & & $\begin{array}{l}\text { Laparoscopic } \\
\text { appendectomy, } n\end{array}$ & $\begin{array}{l}\text { Open } \\
\text { appendectomy, n }\end{array}$ & \\
\hline $\begin{array}{l}\text { Duration of } \\
\text { abdominal pain }\end{array}$ & Median (IQR) & Median (IQR) & $p=0 . x X$ & Median (IQR) & Median (IQR) & $p=0 . x X$ \\
\hline
\end{tabular}

ASA, American Society of Anesthesiologists; BMI, Body Mass Index; SIRS, Systemic Inflammatory Response Syndrome.

be calculated for the treatment strategies, expressing the uncertainty in average costs and effects.

In the cost-utility analyses, the effect of the new treatment is measured by the change in number of QALYs. The ICER will be evaluated against a threshold of $€ 20$ 000/QALY. QALY's will be calculated using the EQ-5D youth and EQ-5D-Proxy questionnaires. As acute appendicitis is an acute disease, disutility might be short-term in our study. Therefore, QALY's will be transformed to quality-adjusted life months.

\section{Budget impact analysis}

\section{General considerations}

Budget impact analysis (BIA) will be performed from the budget holders' perspective, which is the healthcare insurance company. Time-frame will be 5 years as we expect, despite maximum effort, implementation needs some time. Data will be displayed each year taking into account the anticipated market penetration/implementation of the new identified optimal strategies and de-implementation of the current ones. Aim is to predict the effects on budgets after implementation of these new strategies from the stakeholders' perspective (ie, healthcare professionals, patients and parents, and insurance companies).

\section{Cost analysis}

Identification of all healthcare related costs will be recorded per patient. Potential determinants influencing the BIA such as complications and influence of own risk will be taken into account. Indirect non-medical costs (societal/patients perspective) will not be included in this BIA and no discounted costs will be calculated. Total costs will then be calculated for each treatment strategy at 3 months. A simple cost-calculator programmed in a spread sheet will be used in which obtained data is inserted. At completion of this study, based on a parallel problem analysis study of implementation an estimation of the degree of implementation per year will be done. Uncertainty will be taken into account (both in input values (efficacy) and in structural values (implementation)). Multiple scenario analyses will be undertaken to produce plausible alternative scenarios to anticipate this. Total costs prior to and after implementation of the preferred strategy will be calculated and displayed as total impact of the new strategy on the healthcare budget per annum for the Netherlands in terms of cost reduction.

\section{Ethics and dissemination}

\section{Data collection and confidentiality}

A unique code is assigned to every participant of the study. Personal data will not be identifiable through these codes. The encryption key containing the study code and patient identification information is only accessible by the principal investigator. Data are handled confidentially in accordance with the General Data Protection Regulation. Castor Electronic Data Capture will be used for data collection and storage.$^{27}$ This is a web-based electronic database with audit trail. Data collection through electronic case record forms, data analysis and data storage will follow the Good Clinical Practice guidelines. Deidentified data will be stored for at least 15 years. Source data verification will be performed by onsite monitoring of participating sites by an independent and qualified monitor.

\section{Ethics}

The Medical Ethics Review Committee of the Amsterdam UMC, location AMC, declared that the Medical Research involving Human Subjects Act did not apply to this study and, therefore, no official approval was required by national law. The study will be conducted according to the directives of the ICH Good Clinical Practice guidelines and the Declaration of Helsinki.

\section{Withdrawal}

Participants are allowed to withdraw their permission for their data usage at any time without explanation. Data of these patients will not be used in our analysis.

\section{Dissemination plan}

Results of this study will be submitted to an international peer-reviewed scientific journal and for presentation at (inter)national conferences. The results of this study may lead to novel insights into the treatment of complex appendicitis in the paediatric population. If these novel insights warrant changes in the national guidelines for the treatment of complex appendicitis, the nationwide (design and) conduct of the study will aid in its implementation. Furthermore, we will perform an implementation study parallel to this observational study.

\section{Implementation study}

A parallel impact analysis study will be performed to identify promoting and obstructing factors for 
Table 3 Baseline characteristics subgroup 2

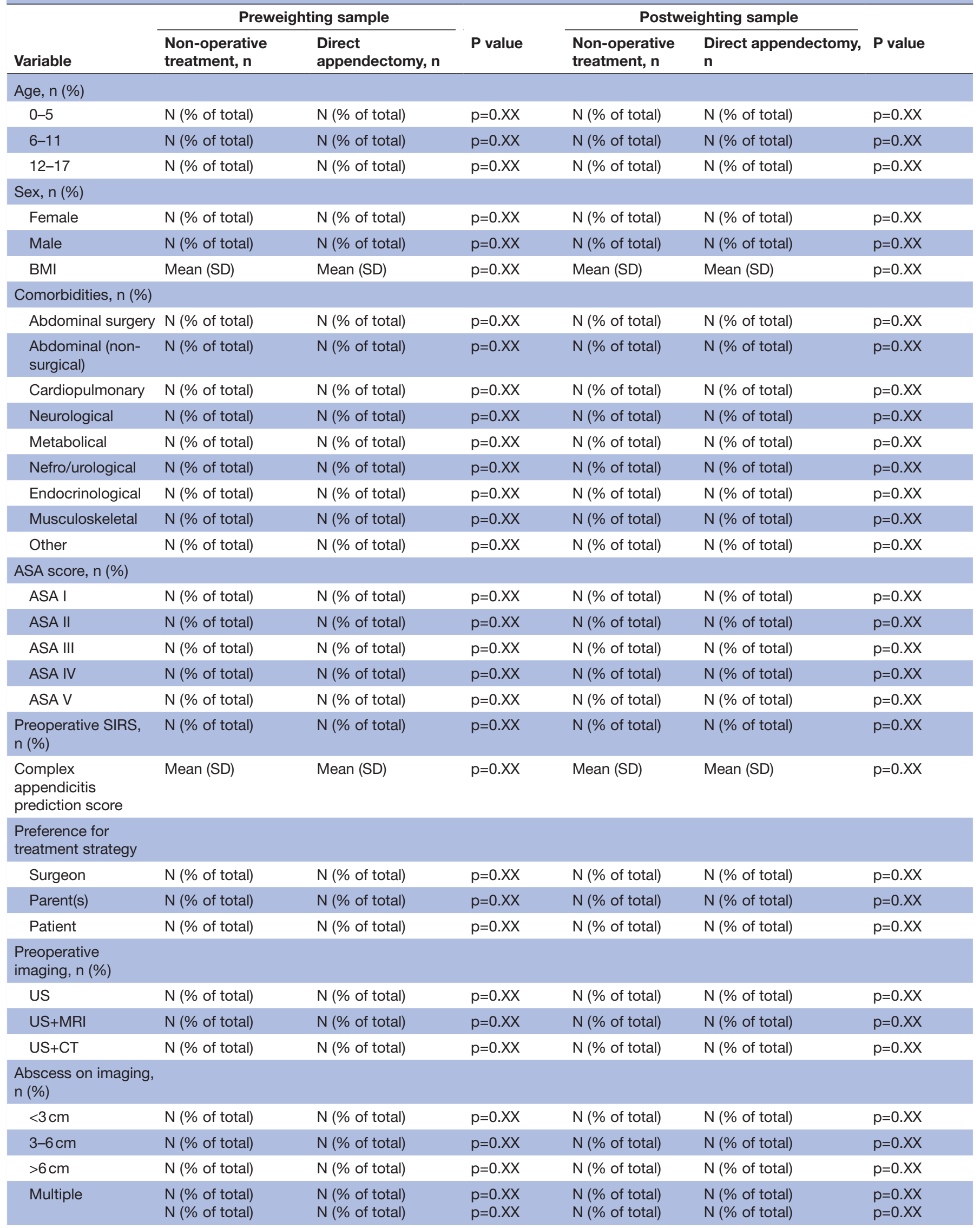

Hospital, n (\%) 
Table 3 Continued

\begin{tabular}{|c|c|c|c|c|c|c|}
\hline \multirow[b]{2}{*}{ Variable } & \multicolumn{2}{|c|}{ Preweighting sample } & \multirow[b]{2}{*}{$P$ value } & \multicolumn{2}{|c|}{ Postweighting sample } & \multirow[b]{2}{*}{$P$ value } \\
\hline & $\begin{array}{l}\text { Non-operative } \\
\text { treatment, } \mathrm{n}\end{array}$ & $\begin{array}{l}\text { Direct } \\
\text { appendectomy, } \mathrm{n}\end{array}$ & & $\begin{array}{l}\text { Non-operative } \\
\text { treatment, } \mathrm{n}\end{array}$ & $\begin{array}{l}\text { Direct appendectomy, } \\
\text { n }\end{array}$ & \\
\hline Teaching & $\mathrm{N}$ (\% of total) & $\mathrm{N}(\%$ of total) & $p=0 . X X$ & $\mathrm{~N}$ (\% of total) & $\mathrm{N}(\%$ of total) & $\mathrm{p}=0 . \mathrm{XX}$ \\
\hline Non-teaching & $\mathrm{N}$ (\% of total) & $\mathrm{N}$ (\% of total) & $p=0 . x X$ & $\mathrm{~N}$ (\% of total) & $\mathrm{N}$ (\% of total) & $p=0 . x x$ \\
\hline $\begin{array}{l}\text { Weekend } \\
\text { presentation, n (\%) }\end{array}$ & $\mathrm{N}$ (\% of total) & $\mathrm{N}$ (\% of total) & $p=0 . x X$ & $\mathrm{~N}$ (\% of total) & $\mathrm{N}$ (\% of total) & $p=0 . x X$ \\
\hline $\begin{array}{l}\text { Days of abdominal } \\
\text { pain }\end{array}$ & Median (IQR) & Median (IQR) & $p=0 . X X$ & Median (IQR) & Median (IQR) & $p=0 . x X$ \\
\hline
\end{tabular}

ASA, American Society of Anesthesiologists; BMI, body mass index; SIRS, Systemic Inflammatory Response Syndrome.

implementation. Staff, representatives and stakeholders on patient, doctor and society level will be asked to participate in this implementation study. Structured interviews with healthcare professionals, patients, parents and other stakeholders will be held in order to identify the best implementation strategy, taking into account the impact of the results on current practice.

\section{DISCUSSION}

The CAPP study aims to identify the optimal treatment strategy for children presenting with complex appendicitis. Current points of debate that are investigated are the optimal surgical approach (laparotomy or laparoscopy) for children presenting with complex appendicitis without mass or abscess formation (subgroup 1); and the choice for direct appendectomy or initial non-operative treatment (consisting of intravenous antibiotics with or without (percutaneous) drainage procedure) for children presenting with complex appendicitis with mass and/or abscess (subgroup 2). At this moment these treatment strategies for paediatric complex appendicitis are all considered standard of care, which leads to significant heterogeneity in daily practice. Recent meta-analyses focusing on the treatment of complex appendicitis in children have confirmed that evidence is scarce, especially for patients that present with complex appendicitis with enlarged mass or abscess formation. ${ }^{10} 1228$ Evidence for (the optimal treatment strategy in) children that present with complex appendicitis without mass or abscess is also relatively scarce. Only two small randomised clinical trials (RCTs) and some cohort studies (mostly historical cohorts) have been published focusing primarily on the overall complication rate of laparoscopic versus open appendectomy. These studies only detected small differences between these operative approaches. ${ }^{10} 2930$ The heterogeneity in current daily practice reflects the lack of evidence and emphasises the need for well-designed studies.

\section{Choice of study design}

The CAPP study is a nation-wide prospective cohort study, that will collect prospective data of more than 1300 patients that are treated for complex appendicitis in more than 30 academic and (large) teaching hospitals in the Netherlands. Therefore, it will be a large prospective study investigating the treatment of both subgroups of complex appendicitis in children. Apart from the measurement of important outcome measures such as the proportion of complications, prospective data will be collected regarding life-impact outcomes (ie, quality of life and return to school), and cost-effectiveness of treatment strategies will be assessed. Furthermore, the study protocol has been designed by a multidisciplinary team, consisting of epidemiologists, paediatricians, infectiologists, gastroenterologists, (interventional) radiologists, patient support groups and (paediatric) surgeons. The nationwide and multidisciplinary character of this study is potentially beneficial for implementation and results will be generalisable to the entire Dutch population of children with complex appendicitis. Moreover, as nowadays global guidelines on the diagnostic work-up and treatment of acute appendicitis are followed by many countries, the management of patients is becoming increasingly comparable. Results of this study are therefore not only generalisable to the Dutch population, but to the international population as well.

Ideally, the comparison between open and laparoscopic appendectomy for complex appendicitis without abscess and/or mass formation and between direct appendectomy and non-operative treatment for patients presenting with appendiceal abscess and/or mass would be investigated in an RCT. However, before the start of the CAPP study, we conducted a nationwide survey that pointed out that there was reluctance among (paediatric) surgeons to participate in an RCT comparing these different treatment strategies in the paediatric population. Reluctance was mostly based on a strong preference of surgeons for one of the treatment strategies. Therefore, we expected that an RCT design would not be feasible and decided 

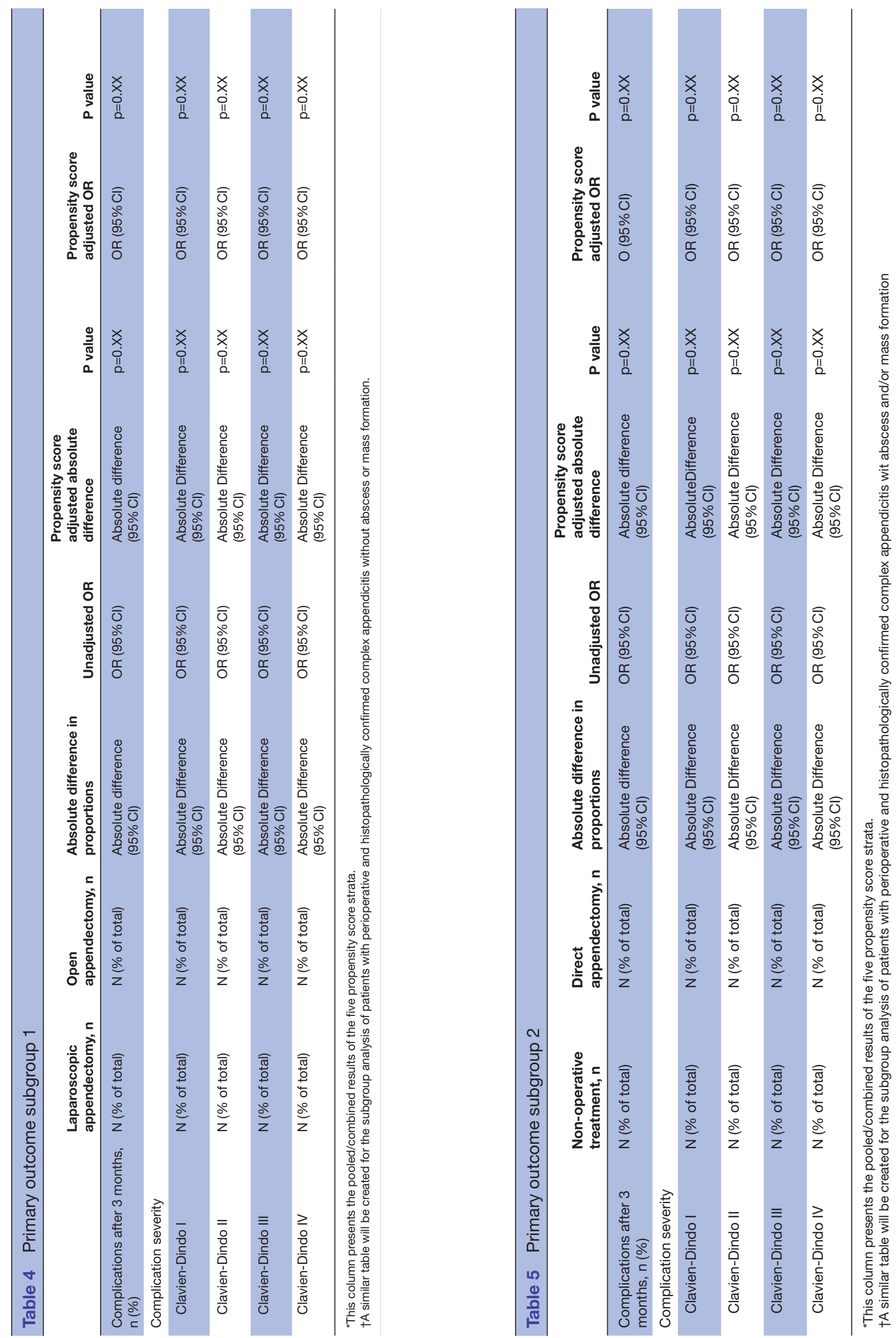

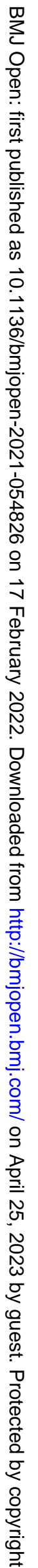


Table 6 Secondary outcomes subgroup 1

Laparoscopic Open appendectomy,

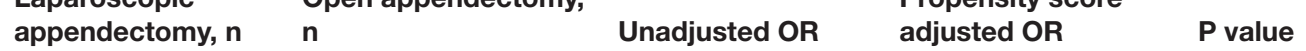

\begin{tabular}{|c|c|c|c|c|c|}
\hline \multicolumn{6}{|l|}{ Any complication } \\
\hline Admission, n (\%) & $\mathrm{N}$ (\% of total) & $\mathrm{N}$ (\% of total) & OR $(95 \% \mathrm{Cl})$ & OR $(95 \% \mathrm{Cl})$ & $p=0 . x X$ \\
\hline 30 days, $\mathrm{n}(\%)$ & $\mathrm{N}$ (\% of total) & $\mathrm{N}$ (\% of total) & OR $(95 \% \mathrm{Cl})$ & OR $(95 \% \mathrm{Cl})$ & $p=0 . x x$ \\
\hline $\begin{array}{l}\text { Superficial site infection (at } 3 \\
\text { months), } \mathrm{n}(\%)\end{array}$ & $\mathrm{N}$ (\% of total) & $\mathrm{N}$ (\% of total) & OR $(95 \% \mathrm{Cl})$ & OR $(95 \% \mathrm{Cl})$ & $p=0 . x x$ \\
\hline
\end{tabular}

obstruction (at 3 months),

$\mathrm{n}(\%)$

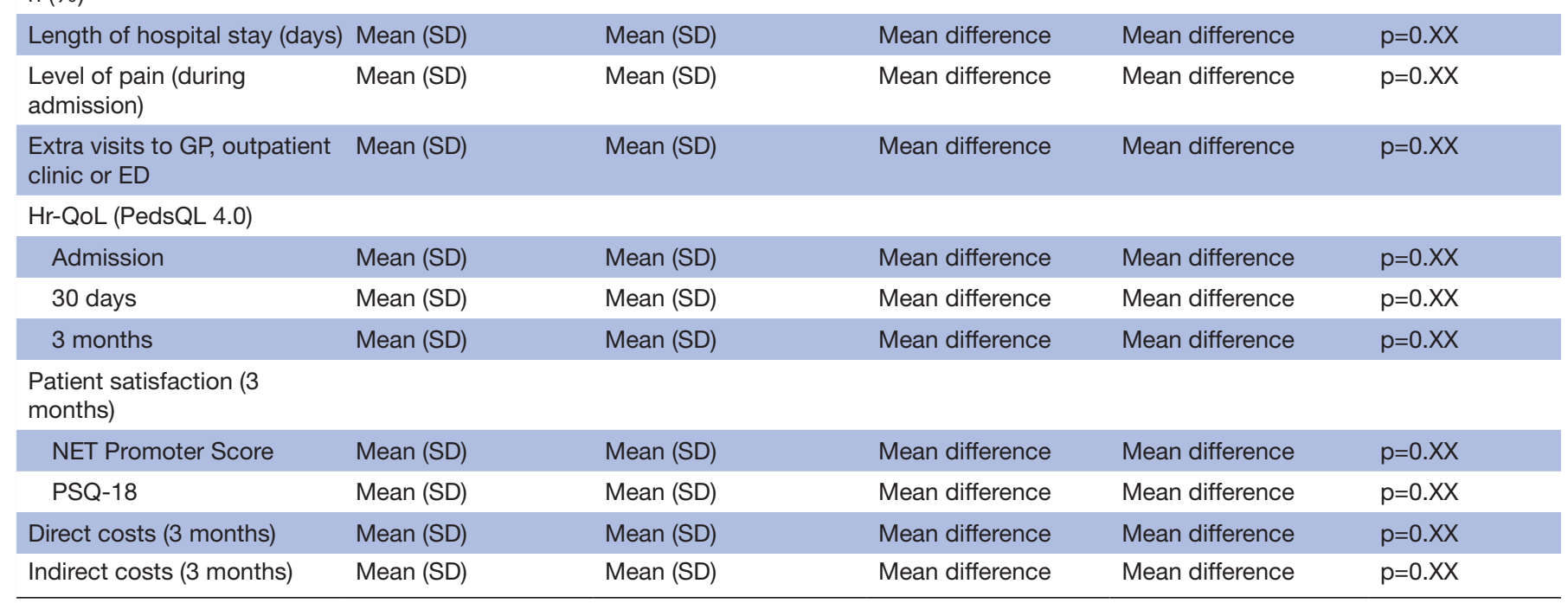

*This column presents the pooled/combined results of the five propensity score strata.

ED, emergency department; GP, general practitioner; Hr-QoL, Health-related Quality of Life; NET, neuro-endocrine tumours; PSQ, Patient Satisfaction Questionnaire.

to perform a nationwide prospective cohort study. Although many clinicians and researchers still consider the RCT design as the gold standard for detecting causal effects, more practical designs such as patient preference and observational designs are increasingly used in large prospective studies. ${ }^{31}$ These study designs also have advantages, because they mimic practice, in which treatment decisions are made by the clinical team. Therefore results from the CAPP study reflect daily clinical practice, including preoperative decision making. Downside of our study design is that it potentially allows for confounding, as the choice of treatment may be affected by patient characteristics, patient/parent preferences, (interventional) radiologist's skills, and surgeon's preferences and skills. For example, the choice for non-operative treatment of children presenting with complex appendicitis with large abscess formation may depend on the presence of an interventional radiologist capable of performing a percutaneous drainage procedure. However, several steps were taken to reduce confounding in this study. Several confounders were identified by our multidisciplinary team before the start of the study and these variables will be taken into account in our propensity score analysis.
To assess the influence of our choice of analyses, it was decided to perform a two-way propensity score analysis, including IPTW and stratification. In this way, we assess the influence of our methods for confounding adjustment on results. Moreover, sample size calculations showed that clinically significant differences in overall complications can be detected with our study design.

Furthermore, with the introduction of standardised treatment strategies steps were taken to reduce heterogeneity in treatment between hospitals. All key points of these standardised treatment strategies are based on the recommendations of the Dutch national guideline. These measures will improve comparability of results of the participating hospitals.

\section{Definition of complex appendicitis}

The CAPP study aims to investigate the complete process of care and outcomes for children with complex appendicitis, including the physician's decision for one of the treatment strategies that are now considered usual care (ie, open or laparoscopic appendectomy, and non-operative treatment or direct appendectomy). To incorporate the preoperative decision-making process, all patients 
Table 7 Secondary outcomes subgroup 2

Non-operative treatment, $n$ Direct appendectomy, n Unadjusted OR

Propensity score adjusted OR P value

\begin{tabular}{|c|c|c|c|c|c|}
\hline \multicolumn{6}{|l|}{ Any complication } \\
\hline Admission, n (\%) & $\mathrm{N}$ (\% of total) & $\mathrm{N}$ (\% of total) & OR $(95 \% \mathrm{Cl})$ & OR $(95 \% \mathrm{Cl})$ & $\mathrm{p}=0 . \mathrm{XX}$ \\
\hline 30 days, $\mathrm{n}(\%)$ & $\mathrm{N}$ (\% of total) & $\mathrm{N}$ (\% of total) & OR $(95 \% \mathrm{Cl})$ & OR $(95 \% \mathrm{Cl})$ & $p=0 . x X$ \\
\hline $\begin{array}{l}\text { Superficial site infection (at } 3 \\
\text { months), } n(\%)\end{array}$ & $\mathrm{N}$ (\% of total) & $\mathrm{N}$ (\% of total) & OR $(95 \% \mathrm{Cl})$ & OR $(95 \% \mathrm{Cl})$ & $p=0 . x x$ \\
\hline
\end{tabular}
obstruction (at 3 months),

$\mathrm{n}(\%)$

\begin{tabular}{|c|c|c|c|c|c|}
\hline Length of hospital stay (days) & Mean (SD) & Mean (SD) & Mean difference & Mean difference & $p=0 . x x$ \\
\hline $\begin{array}{l}\text { Level of pain (during } \\
\text { admission) }\end{array}$ & Mean (SD) & Mean (SD) & Mean difference & Mean difference & $p=0 . x X$ \\
\hline $\begin{array}{l}\text { Extra visits to GP, outpatient } \\
\text { clinic or emergency } \\
\text { department }\end{array}$ & Mean (SD) & Mean (SD) & Mean difference & Mean difference & $p=0 . x x$ \\
\hline $\begin{array}{l}\text { No appendectomy after } 3 \\
\text { months, } \mathrm{n}(\%)\end{array}$ & $\mathrm{N}$ (\% of total) & - & - & - & - \\
\hline $\begin{array}{l}\text { Early failure of non-operative } \\
\text { treatment, } \mathrm{n}(\%)\end{array}$ & $\mathrm{N}$ (\% of total) & - & - & - & - \\
\hline $\begin{array}{l}\text { Interval appendectomy (at } 3 \\
\text { months), } \mathrm{n}(\%)\end{array}$ & $\mathrm{N}(\%$ of total) & - & - & - & - \\
\hline 3 months & Mean (SD) & Mean (SD) & Mean difference & Mean difference & $p=0 . x x$ \\
\hline \multicolumn{6}{|l|}{$\begin{array}{l}\text { Patient satisfaction ( } 3 \\
\text { months) }\end{array}$} \\
\hline NET Promoter Score & Mean (SD) & Mean (SD) & Mean difference & Mean difference & $p=0 . x x$ \\
\hline PSQ-18 & Mean (SD) & Mean (SD) & Mean difference & Mean difference & $p=0 . x X$ \\
\hline Direct costs (3 months) & Mean (SD) & Mean (SD) & Mean difference & Mean difference & $p=0 . x x$ \\
\hline Indirect costs (3 months) & Mean (SD) & Mean (SD) & Mean difference & Mean difference & $\mathrm{p}=0 . \mathrm{XX}$ \\
\hline
\end{tabular}

${ }^{*}$ This column presents the pooled/combined results of the five propensity score strata.

GP, general practitioner; Hr-QoL, Health-related Quality of Life; NET, neuro-endocrine tumours; PSQ, Patient Satisfaction Questionnaire.

with a presumed diagnosis of complex appendicitis will be included in the study pre-operatively. Therefore, the inclusion and exclusion criteria are mostly based on the complex appendicitis prediction score that was previously developed by our research team. This scoring system combines clinical, biochemical and radiological variables in order to differentiate between simple and complex appendicitis. A cut-off point of four points is used for inclusion of patients in this study. Despite the diagnostic accuracy of $90 \%$, inevitably some patients with simple appendicitis will be included in this study. ${ }^{15}$ Therefore we plan to perform an analysis on all included patients and an additional analysis that includes only patients with a diagnosis of complex appendicitis that is perioperatively and/or histopathologically confirmed. Classification of simple and complex appendicitis remains challenging, as no uniform definition for complex appendicitis is available yet. In the current literature various terms and definitions are used for appendiceal mass and complex appendicitis. Terms that are frequently used to describe the spectrum of complex appendicitis are signs of necrosis (black, blue or purple colour change), a visible hole in the appendix, an extraluminal fecolith, generalised peritonitis, and an appendiceal mass or abscess. ${ }^{23} 3233$ Furthermore, 'perforated appendicitis', 'complex appendicitis' and 'complicated' appendicitis are terms that are used interchangeably. The same applies for the terms appendiceal 'mass' and 'phlegmon'. Therefore in this study, it was decided to use an objective classification of perioperative and postoperative variables, that is, the classification suggested by Bhangu et al. ${ }^{23}$ 


\section{Choice of primary outcome}

Determining the primary outcome measure for studies comparing standard treatment strategies for complex appendicitis is challenging. Recently, an international consensus study led to the development of a core outcome set for clinical trials investigating any type of treatment of children with acute simple appendicitis. This core outcome set was developed in collaboration with several different stakeholders such as patients, parents, researchers and physicians. The complication rate appeared to be an important outcome that was mentioned by all stakeholders. ${ }^{14}$ Unfortunately, up till now, no core outcome set has been developed for studies investigating the optimal treatment strategy for children presenting with complex appendicitis. Therefore, the CAPP study minimally adheres to the outcomes as reported in the core outcome set for studies investigating the treatment of simple appendicitis. In line with this core outcome set, and based on previous qualitative studies investigating possible promoting and obstructing factors for implementation, we decided to choose the proportion of patients experiencing complications within 3 months after the start of treatment as primary outcome. In addition, we think that the overall complication rate is the most relevant outcome that can persuade doctors (and patients) to choose between the treatment strategies.

Previous studies have shown that the differences in complication rate between the treatment strategies that are investigated in this study might be relatively small. Therefore, it could be possible that no difference in complication rate will be found in this large prospective cohort study. If no clinically relevant difference is found in the primary outcome, the difference in secondary outcomes, such as Hr-QoL and cost-effectiveness, may become more important. Secondary outcomes of this study were also chosen to reflect the same five core areas as the core outcome set for children with simple appendicitis, that is, death, physiological/clinical manifestations, life impact, resource use and adverse events. Besides our primary outcome (overall complication rate), life impact outcomes (ie, paediatric quality of life, return to school or normal activities) and resource use outcomes (ie, hospital readmission, need for reoperation, need for appendectomy after initial non-operative treatment) are taken into account. High-quality data on these secondary outcomes can furthermore be used by the treating physician to inform patients on the advantages and disadvantages of the treatment options, which will facilitate shared decision making.

\section{Length of follow-up}

The majority of complications after appendectomy occur within 3 months after the start of treatment. Although longterm complications (>30 days after appendectomy), such as adhesive small bowel obstruction and incisional hernia, do occur after appendectomy in children, their prevalence is reported to be less than $1 \% \cdot{ }^{34}$ Furthermore, as appendicitis is an acute disease it is expected to affect Hr-QoL and medical costs for only a short period of time. As it is expected that the majority of children is recovered within 3 months, a follow-up duration of 3 months was chosen for this study. However, all patients treated in this prospective cohort study will be asked for their consent to approach them to participate in future studies in which their long-term outcomes (more than 3 months) will be investigated. Information regarding the long-term results of non-operative treatment and the necessity of interval appendectomy is scarce in children. One randomised controlled trial has been published recently in which children treated non-operatively for appendix mass were randomised between active observation or planned interval appendectomy. ${ }^{35}$ This study showed a rate of $6 \%$ severe complications after interval appendectomy, whereas only $12 \%$ of children under active observation developed recurrent appendicitis within 1year follow-up. Therefore, interval appendectomy was not incorporated as a routine procedure after non-operative treatment in the CAPP study. Opponents of this strategy point to the possibility of missing neuro-endocrine tumours (NETs) of the appendix. However, several studies have shown that NETs are rarely found at histopathological examination $(0 \%-0.4 \%){ }^{36-39}$

Long-term follow-up would be of additional interest for those patients that present with a faecolith. Previous studies investigating non-operative treatment in both patients with simple appendicitis and complex appendicitis, have reported that a faecolith might increase the risk of recurrent appendicitis. ${ }^{40-42}$ As the CAPP study only has a follow-up period of 3 months, important information regarding recurrent appendicitis in the group of patients that is treated non-operatively would be missed. Therefore, all patients that are treated in this study will be asked to participate in long-term follow-up.

This nationwide prospective cohort study will be the first study that provides high-quality evidence regarding the optimal treatment strategy for complex appendicitis in children. Results of this study will be used to support recommendations for (inter) national guidelines regarding the treatment of acute appendicitis, which will improve shared decision making and ultimately lead to uniform optimal treatment of complex appendicitis in the paediatric population.

\section{Author affiliations \\ ${ }^{1}$ Department of Pediatric Surgery, Emma Children's Hospital, Amsterdam UMC, University of Amsterdam \& Vrije Universiteit Amsterdam, Amsterdam, The Netherlands \\ ${ }^{2}$ Pediatric Clinical Research Office, Amsterdam UMC, University of Amsterdam \& Vrije Universiteit Amsterdam, Amsterdam, The Netherlands \\ ${ }^{3}$ Knowledge Institute of the Dutch Association of Medical Specialists, Utrecht, The Netherlands \\ ${ }^{4}$ Department of Obstetrics and Gynaecology, Amsterdam UMC, University of Amsterdam \& Vrije Universiteit Amsterdam, Amsterdam, The Netherlands ${ }^{5}$ Centre for Reproductive Medicine, Amsterdam UMC-Location AMC, Amsterdam, The Netherlands}

Collaborators CAPP collaborative study group: H A Rippen (Dutch Child and Hospital Foundation, Utrecht, the Netherlands), J Berkhof (Department of Epidemiology and Biostatistics, VU University Medical Center, Amsterdam, the Netherlands), B G P Koot (Department of Pediatric Gastroenterology, Emma Children's Hospital, Amsterdam UMC, University of Amsterdam, Amsterdam, 
the Netherlands), M van der Kuip (Department of Pediatric Infectious Diseases and Immunology, Emma Children's Hospital, Amsterdam UMC, Amsterdam, the Netherlands), R R van Rijn (Department of Radiology and Nuclear Medicine, Emma Children's Hospital, University of Amsterdam, Amsterdam, the Netherlands), $\mathrm{H} \mathrm{J}$ Bonjer (Department of Surgery, Amsterdam UMC, University of Amsterdam \& Vrije Universiteit Amsterdam, Amsterdam, the Netherlands), J Jansen (Department of Surgery, Admiraal de Ruyter Hospital, Goes, the Netherlands), M A Lijkwan (Department of Surgery, Albert Schweitzer Hospital, Dordrecht, the Netherlands), G D Musters (Department of Surgery, Albert Schweitzer Hospital, Dordrecht, the Netherlands), P Boele van Hensbroek13, M Springer (Department of Surgery, Amphia, Breda, the Netherlands), F C van Eijck (Department of Surgery, Bravis Hospital, Bergen op Zoom, the Netherlands), M D P Luyer (Department of Surgery, Catharina Hospital, Eindhoven, the Netherlands), A Jairam (Department of Surgery, Catharina Hospital, Eindhoven, the Netherlands), L M de Widt (Department of Surgery, Dijklander Hospital, Hoorn, the Netherlands), M Knaapen (Department of Surgery, Dijklander Hospital, Hoorn, the Netherlands), C M G Keyzer-Dekker (Department of Pediatric Surgery, Sophia Children's Hospital, Erasmus University Medical Center, Rotterdam, the Netherlands), R M H Wijnen (Department of Pediatric Surgery, Sophia Children's Hospital, Erasmus University Medical Center, Rotterdam, the Netherlands), G M P Diepenhorst (Department of Surgery, Flevo Hospital, Almere, the Netherlands), K M A Dreuning (Department of Surgery, Flevo Hospital, Almere, the Netherlands), M M Poelman (Department of Surgery, Franciscus Gasthuis \& Vlietland, Rotterdam, the Netherlands), D Verver (Department of Surgery, Franciscus Gasthuis \& Vlietland, Rotterdam, the Netherlands), P van Duijvendijk (Department of Surgery, Gelre Hospitals, Apeldoorn/Zutphen, the Netherlands), M E van der Sande (Department of Surgery, Gelre Hospitals, Apeldoorn/Zutphen, the Netherlands), J W A Oosterhuis (Department of Surgery, Haaglanden Medical Center, The Hague, the Netherlands), G W Zijp (Department of Pediatric Surgery, Juliana Children's Hospital, Haga Hospital, The Hague, the Netherlands), E H Pasveer (Department of Pediatric Surgery, Juliana Children's Hospital, Haga Hospital, The Hague, the Netherlands), R P R Groenendijk (Department of Surgery, IJsselland Hospital, Capelle aan den IJssel, the Netherlands), J L A van Vugt (Department of Surgery, IJsselland Hospital, Capelle aan den IJssel, the Netherlands), W J Vles (Department of Surgery, Ikazia Hospital, Rotterdam, the Netherlands), C A Selles (Department of Surgery, Ikazia Hospital, Rotterdam, the Netherlands), V B Nieuwenhuijs (Department of Surgery, Isala, Zwolle, the Netherlands), J T Hoffman (Department of Surgery, Isala, Zwolle, the Netherlands), J W A Leijtens (Department of Surgery, Laurentius Hospital, Roermond, the Netherlands), E G M Vosbeek (Department of Surgery, Laurentius Hospital, Roermond, the Netherlands), C C van Rossem (Department of Surgery, Maasstad Hospital, Rotterdam, the Netherlands), M P Gaspersz (Department of Surgery, Maasstad Hospital, Rotterdam, the Netherlands), M H M Bender (Department of Surgery, Maxima Medical Center, Veldhoven, The Netherlands), B J Corten (Department of Surgery, Maxima Medical Center, Veldhoven, The Netherlands), E C J Consten (Department of Surgery, Meander Medical Center, Amersfoort, the Netherlands; Department of Surgery, University Medical Center Groningen, Groningen, the Netherlands), M F J Seesing (Department of Surgery, Meander Medical Center, Amersfoort, the Netherlands), T S Bijlsma (Department of Surgery, Noordwest Ziekenhuisgroep, Alkmaar, the Netherlands), S M L The (Department of Surgery, Noordwest Ziekenhuisgroep, Alkmaar, the Netherlands), L E Janssen (Department of Surgery, Noordwest Ziekenhuisgroep, Alkmaar, the Netherlands), V J Leijdekkers (Department of Surgery, OLVG, Amsterdam the Netherlands), M V Nijenhuis (Department of Surgery, OLVG, Amsterdam the Netherlands), S M B I Botden (Department of Pediatric Surgery, Radboudumc - Amalia Children's Hospital, Nijmegen, the Netherlands), M Joosten (Department of Pediatric Surgery, Radboudumc - Amalia Children's Hospital, Nijmegen, the Netherlands), A L A Bloemendaal (Department of Surgery, Reinier de Graaf Gasthuis, Delft, the Netherlands), C F J M BlankenPeeters (Department of Surgery, Rijnstate, Arnhem, the Netherlands), W M IJgosse (Department of Surgery, Rijnstate, Arnhem, the Netherlands), A Meij-de Vries (Department of Surgery, Red Cross Hospital, Beverwijk, the Netherlands), M M Bruntink (Department of Surgery, Red Cross Hospital, Beverwijk, the Netherlands), P M N Y H Go (Department of Surgery, St. Antonius Hospital, Nieuwegein, the Netherlands), M Pool (Department of Surgery, St. Antonius Hospital, Nieuwegein, the Netherlands), S J Oosterling (Department of Surgery, Spaarne Gasthuis, Haarlem, the Netherlands), T C Derksen (Department of Surgery, Spaarne Gasthuis, Haarlem, the Netherlands), A A W van Geloven (Department of Surgery, Tergooi, Hilversum, the Netherlands), T T Poels (Department of Surgery, Tergooi, Hilversum, the Netherlands), J B F Hulscher (Department of Pediatric Surgery, University Medical Center Groningen, Groningen, the Netherlands), F C den Boer (Department of Surgery, Zaans Medical Center, Zaandam, the Netherlands), S F Hardon (Department of Surgery, Zaans Medical Center, Zaandam, the Netherlands), F P Garssen (Department of Surgery, Amstelland Hospital, Amstelveen, the Netherlands), T
Wagner (Department of Surgery, Amstelland Hospital, Amstelveen, the Netherlands), M F Lutke Holzik (Department of Surgery, Ziekenhuisgroep Twente, Almelo, the Netherlands), M B G M Decaestecker (Department of Surgery, Ziekenhuisgroep Twente, Almelo, the Netherlands), E G Boerma (Department of Surgery, Zuyderland Medical Center, Heerlen/Sittard, the Netherlands), D Schweitzer (Department of Surgery, Zuyderland Medical Center, Heerlen/Sittard, the Netherlands).

Contributors All authors have contributed to the design of the study protocol. The protocol was drafted by PvA, RRG and RB and refined by JHvdL, MCvdW, RvE, JPMD and ELWvH. Statistical advice was provided by JHvdL, MCvdW and RvE. The manuscript was drafted by PvA and refined by all other authors. All authors have read and approved the final manuscript. All local investigators who are responsible for the conduct of the study in the participating centres are acknowledged in the CAPP collaborative study group. They have all read and approved the final manuscript.

Funding This work was supported by The Netherlands Organisation for Health Research and Development (ZonMw) (grant number: 80-85009-98-2007).

Competing interests None declared.

Patient consent for publication Not applicable.

Provenance and peer review Not commissioned; externally peer reviewed.

Supplemental material This content has been supplied by the author(s). It has not been vetted by BMJ Publishing Group Limited (BMJ) and may not have been peer-reviewed. Any opinions or recommendations discussed are solely those of the author(s) and are not endorsed by BMJ. BMJ disclaims all liability and responsibility arising from any reliance placed on the content. Where the content includes any translated material, BMJ does not warrant the accuracy and reliability of the translations (including but not limited to local regulations, clinical guidelines, terminology, drug names and drug dosages), and is not responsible for any error and/or omissions arising from translation and adaptation or otherwise.

Open access This is an open access article distributed in accordance with the Creative Commons Attribution Non Commercial (CC BY-NC 4.0) license, which permits others to distribute, remix, adapt, build upon this work non-commercially, and license their derivative works on different terms, provided the original work is properly cited, appropriate credit is given, any changes made indicated, and the use is non-commercial. See: http://creativecommons.org/licenses/by-nc/4.0/.

\section{ORCID iD}

Paul van Amstel http://orcid.org/0000-0003-0992-5547

\section{REFERENCES}

1 Addiss DG, Shaffer N, Fowler BS, et al. The epidemiology of appendicitis and appendectomy in the United States. Am J Epidemiol 1990;132:910-25

2 Anderson JE, Bickler SW, Chang DC, et al. Examining a common disease with unknown etiology: trends in epidemiology and surgical management of appendicitis in California, 1995-2009. World J Surg 2012;36:2787-94.

3 van Rossem CC, Bolmers MDM, Schreinemacher MHF, et al. Prospective nationwide outcome audit of surgery for suspected acute appendicitis. Br J Surg 2016;103:144-51.

4 Andersson RE. The natural history and traditional management of appendicitis revisited: spontaneous resolution and predominance of prehospital perforations imply that a correct diagnosis is more important than an early diagnosis. World J Surg 2007;31:86-92.

5 Cobben LP, de Van Otterloo AM, Puylaert JB. Spontaneously resolving appendicitis: frequency and natural history in 60 patients. Radiology 2000;215:349-52.

6 Rubér M, Andersson M, Petersson BF, et al. Systemic Th17-like cytokine pattern in gangrenous appendicitis but not in phlegmonous appendicitis. Surgery 2010;147:366-72.

7 Di Saverio S, Podda M, De Simone B, et al. Diagnosis and treatment of acute appendicitis: 2020 update of the WSES Jerusalem guidelines. World J Emerg Surg 2020;15:27.

8 Gorter RR, Eker HH, Gorter-Stam MAW, et al. Diagnosis and management of acute appendicitis. EAES consensus development conference 2015. Surg Endosc 2016;30:4668-90.

9 Bolmers MD, van Rossem CC, Gorter RR, et al. Imaging in pediatric appendicitis is key to a low normal appendix percentage: a national audit on the outcome of appendectomy for appendicitis in children. Pediatr Surg Int 2018;34:543-51.

10 Markar SR, Blackburn S, Cobb R, et al. Laparoscopic versus open appendectomy for complicated and uncomplicated appendicitis in children. J Gastrointest Surg 2012;16:1993-2004. 
11 Cheng Y, Xiong X, Lu J, et al. Early versus delayed appendicectomy for appendiceal phlegmon or abscess. Cochrane Database Syst Rev 2017;6:CD011670.

12 Simillis C, Symeonides P, Shorthouse AJ, et al. A meta-analysis comparing conservative treatment versus acute appendectomy for complicated appendicitis (abscess or phlegmon). Surgery 2010;147:818-29.

13 Bom WJ, Knaapen M, Gorter RR. Revised guideline for acute appendicitis. Amendments to diagnostics and treatment]. Ned Tijdschr Geneeskd 2020;164 https://pubmed.ncbi.nlm.nih.gov/ 32406636/

14 Knaapen M, Hall NJ, van der Lee JH, et al. Establishing a core outcome set for treatment of uncomplicated appendicitis in children: study protocol for an international Delphi survey. BMJ Open 2019;9:e028861.

15 Gorter RR, van den Boom AL, Heij HA, et al. A scoring system to predict the severity of appendicitis in children. J Surg Res 2016;200:452-9.

16 Dindo D, Demartines N, Clavien P-A. Classification of surgical complications: a new proposal with evaluation in a cohort of 6336 patients and results of a survey. Ann Surg 2004;240:205-13.

17 Berríos-Torres SI, Umscheid CA, Bratzler DW, et al. Centers for disease control and prevention guideline for the prevention of surgical site infection, 2017. JAMA Surg 2017;152:784-91.

18 Varni JW, Seid M, Rode CA. The PedsQL: measurement model for the pediatric quality of life inventory. Med Care 1999;37:126-39.

19 Wille N, Badia X, Bonsel G, et al. Development of the EQ-5D-Y: a child-friendly version of the EQ-5D. Qual Life Res 2010;19:875-86.

20 Thayaparan AJ, Mahdi E. The patient satisfaction questionnaire short form (PSQ-18) as an adaptable, reliable, and validated tool for use in various settings. Med Educ Online 2013;18:21747.

21 Bouwmans C, Hakkaart-van Roijen L, Koopmanschap M. Handleiding iMTA medical cost questionnaire (IMCQ. Rotterdam: iMTA, Erasmus Universiteit Rotterdam, 2013.

22 Bouwmans $\mathrm{C}$, Krol M, Severens $\mathrm{H}$, et al. The iMTA productivity cost questionnaire: a standardized instrument for measuring and Valuing health-related productivity losses. Value Health 2015;18:753-8.

23 Bhangu A, Søreide K, Di Saverio S, et al. Acute appendicitis: modern understanding of pathogenesis, diagnosis, and management. The Lancet 2015;386:1278-87.

24 Rosenbaum PR, Rubin DB. The central role of the propensity score in observational studies for causal effects. Biometrika 1983;70:41-55.

25 Austin PC. An introduction to propensity score methods for reducing the effects of confounding in observational studies. Multivariate Behav Res 2011;46:399-424.

26 Austin PC, Stuart EA. Moving towards best practice when using inverse probability of treatment weighting (IPTW) using the propensity score to estimate causal treatment effects in observational studies. Stat Med 2015;34:3661-79.

27 Castor EDC. Castor electronic data capture, 2019. Available: https:// castoredc.com [Accessed 28 Aug 2019].
28 van Amstel P, Sluckin TC, van Amstel T, et al. Management of appendiceal mass and abscess in children; early appendectomy or initial non-operative treatment? A systematic review and metaanalysis. Surg Endosc 2020;34:5234-49.

29 Lintula H, Kokki H, Vanamo K, et al. Laparoscopy in children with complicated appendicitis. J Pediatr Surg 2002;37:1317-20.

30 Oka T, Kurkchubasche AG, Bussey JG, et al. Open and laparoscopic appendectomy are equally safe and acceptable in children. Surg Endosc 2004;18:242-5.

31 Minneci PC, Hade EM, Lawrence AE, et al. Association of Nonoperative management using antibiotic therapy vs laparoscopic appendectomy with treatment success and disability days in children with uncomplicated appendicitis. JAMA 2020;324:581-93.

32 Blakely ML, Williams R, Dassinger MS, et al. Early vs interval appendectomy for children with perforated appendicitis. Arch Surg 2011;146:660-5.

33 St Peter SD, Sharp SW, Holcomb GW, et al. An evidence-based definition for perforated appendicitis derived from a prospective randomized trial. J Pediatr Surg 2008;43:2242-5.

34 Rasmussen T, Fonnes S, Rosenberg J. Long-Term complications of appendectomy: a systematic review. Scand J Surg 2018;107:189-96.

35 Hall NJ, Eaton S, Stanton MP, et al. Active observation versus interval appendicectomy after successful non-operative treatment of an appendix mass in children (China study): an open-label, randomised controlled trial. Lancet Gastroenterol Hepatol 2017;2:253-60.

36 Fouad D, Kauffman JD, Chandler NM. Pathology findings following interval appendectomy: should it stay or go? J Pediatr Surg 2020;55:737-41.

37 Gorter RR, van Amstel P, van der Lee JH, et al. Unexpected findings after surgery for suspected appendicitis rarely change treatment in pediatric patients; results from a cohort study. J Pediatr Surg 2017;52:1269-72.

38 Kim SS, Kays DW, Larson SD, et al. Appendiceal carcinoids in children--management and outcomes. J Surg Res 2014;192:250-3.

39 Otake S, Suzuki N, Takahashi A, et al. Histological analysis of appendices removed during interval appendectomy after conservative management of pediatric patients with acute appendicitis with an inflammatory mass or abscess. Surg Today 2014;44:1400-5.

40 Ein SH, Langer JC, Daneman A. Nonoperative management of pediatric ruptured appendix with inflammatory mass or abscess: presence of an appendicolith predicts recurrent appendicitis. $J$ Pediatr Surg 2005;40:1612-5.

41 Mahida JB, Lodwick DL, Nacion KM, et al. High failure rate of nonoperative management of acute appendicitis with an appendicolith in children. J Pediatr Surg 2016;51:908-11.

42 Tanaka $\mathrm{Y}$, Uchida $\mathrm{H}$, Kawashima $\mathrm{H}$, et al. Long-term outcomes of operative versus nonoperative treatment for uncomplicated appendicitis. J Pediatr Surg 2015;50:1893-7. 